\title{
Prevalence of Ixodid Ticks of Cattle in Sedal District of Khamashi Zone, Benishangul Gumuz Regional State, Ethiopia
}

\author{
Mulugeta Tegegn Morka Amante* \\ 1.School of Veterinary Medicine, Wollega University, Nekemte, Ethiopia \\ 2.Asossa Veterinary Regional Laboratory, Asossa, Ethiopia \\ * Corresponding author Information, Wollega University, P. O. Box 394, Nekemte, Oromia, Ethiopia
}

\begin{abstract}
A cross section study was conducted from October 2016 to April 2017 in Sedal district of Khamashi zone of Benishangul Gumuz Regional State with the objectives of determining the prevalence and Risk factors associated with tick infestations and to identify different tick genera and their species. The prevalence of ticks in relation to age, sex, body condition, and origin of animal was studied. Out of the 384 cattle examined, 298 (77.6\%) were found with being infested by one or more tick species. About 2687 ticks were collected and the collected tick were preserved with $70 \%$ alcohol and were identified to genera and species level by using stereo-microscope. From the total ticks collected, Three genera's namely; Amblyomma, Rhipicephalus, and Hyalomma and five species were identified of, which Amblyomma variegatum was the most abundant tick species comprising of $26.8 \%$ of the total collection and the least abundant tick species was Rhipicephalus bursa $(0.8 \%)$. The association of the prevalence of tick infestation by different risk factors was assessed to be statistically insignificant between sexes and body condition of cattle. Male animals were not significantly infested than females, which were $36.0 \%$ and $51.0 \%$, respectively. The prevalence of tick infestation was was found highest in poor body condition animals $(27.9 \%)$ while in medium and good body condition, it was found $(25.8 \%)$ and $(24 \%)$, respectively. However, there was statistically significant $(\mathrm{p}<0.05, \mathrm{p}=0.04)$ variation between the age groups; adult cattle were infested than the old and young age group, which were $33.8 \%, 27.3 \%$ ) than $16.5 \%$ respectively. Tick infestation of cattle was more prevalent in Gokaya (23.4\%) and Meguchay (19.1\%) than Diza (18.2\%) and Shawa (16.9\%) cattle. It was concluded that tick species identified which was a threat to the cattle population in Sedal district, irrespective of age, sex, origin, body condition of the animal of the study area. In line with this, we recommend further study to assess the ecological, management and host related factors influencing tick infestation, there by appropriate control measure should be put in place.
\end{abstract}

Keywords: Tick, Cattle, Ixodid Tick, Prevalence

DOI: $10.7176 / \mathrm{JNSR} / 11-17-02$

Publication date:September $30^{\text {th }} 2020$

\section{Introduction}

Ethiopia is believed to have the largest livestock population in Africa, approximately 53.99 million cattle, 25.5 million sheep and 24.06 million goats, 1.91 million horses, 6.75 million donkeys, 0.35 million mules, 0.92 million camels, 50.38 million poultry and 5.21 million bee hives. This livestock sector has been contributing considerable portion to the economy of the country, and still promising to rally round the economic development of the country (CSA, 2013).

In Ethiopia, livestock production remains crucial and represents a major asset among resource-poor small holder farmers by providing milk, meat, skin, manure and traction force (Mesfin and Lemma, 2001). The contribution of livestock to the national economy particularly with regard to foreign currency earnings is through exploration of live animal, meat and skin and hides (MoARD, 2008).

Poor health and productivity of animal due to disease has considerably become the major stumbling block to the potential of livestock industry (Onu, and Shiferaw, 2013). Now a day parasitism represents a major obstacle to development and utilization of animal resource. In Ethiopia, ectoparasites in ruminant cause serious economic losses to small holder farmers, the tanning industry and country as a while through mortality of animals, decreased production, down grading and rejection of skin and hide (Regasa et al., 2015). From the ectoparasites, ticks are ranked as the most economically important of livestock in tropics including sub-Saharan Africa (Lorusso et al., 2013).

Ticks are small, wingless ectoparasitic arachinid arthropods that are cosmopolitan and prevalent in warmer climates (Olwocho et al., 2009). Ticks cause substantial losses in cattle production, in terms of diseases, reduced productivity and fertility and often death, and are economically the most important ecto-parasites of cattle (Eyo et al., 2014). Ticks suck blood; damage hides and skins introduce toxins and predispose cattle to myiasis and dermatophilosis (Yiwombe, 2013).

Furthermore, they reduce bodyweight gains and milk yield, in addition to creating sites for secondary invasion by pathogenic organisms (Marufu, 2008). More significantly; ticks transmit diseases from infected cattle to healthy ones. Ticks transmit greater variety of pathogenic micro-organisms than any other arthropod vector group, and are 
among the most important vectors of diseases affecting animals (Yiwombe, 2013).

According to (Walker et al., 2003) ticks which are considered to be most important to health of domestic animal in Africa comprise about seven genera. Among these genera, the main tick genera found in Ethiopia include Amblyomma, subgenus Rhipicephalus (Boophilus), Haemaphysalis, Hyalomma and Rhipicephalus. The genus Ambylomma and Rhipicephalus are predominating in many parts of country, Hyalomma and sub genus Rhipicephalus (Boophilus) also have significant role (Gebre et al., 2001).

Due to economic and veterinary importance of ticks, their control and transmission of tick borne diseases remain challenge for the cattle industry of the world and it is a priority for many countries in tropical and subtropical regions (Rajput et al, 2006). In Ethiopia, there are about 47 species of ticks found on livestock and most of them have importance as vector and disease causing agent and also have damaging effect on skin and hide production (Tadesse and Sultan, 2014).

Although different tick species are widely distributed in Ethiopia and a number of researchers reported the distribution and abundance of tick species in different parts of the country; it has not been yet enough to have the country wide distribution figures and their burden. Thus, the current study was designed in in Sedal district with the following objectives.

$>$ To determine the prevalence and associated risk factors with tick infestations,

$>$ To identify different tick genera and their species in the study area

\section{Materials and Methods}

\subsection{Study area}

This study was conducted in Sedal district of Khamashi zone of Benishangul Gumuz Regional State. Sedal is the capital town, about $199 \mathrm{~km}$ from the zonal capital Kamshi and the district is about $624 \mathrm{~km}$ from Finfine. It has 15 rural village which have total household population of 23,000 (CSA, 2015). The region is found in the north west of the country between latitude of 9 and $11^{\circ} \mathrm{N}$ and longitude of 34 and $35^{\circ} \mathrm{E}$ and its altitude range is $1500-1900$ meter above sea level. Annual rain fall is between $1350-1400 \mathrm{~mm}$ with unimodal type of rain fall that occurs between April and October. Annual temperature ranges between $21^{\circ} \mathrm{c}-35^{\circ} \mathrm{c}$. The livelihood of the society largely depends on mixed livestock and crop production having livestock population of 36,735 Cattle, 10732 Goat, 3739 Sheep, 4467 Equines, 41438 Poultry and 23423 beehives (CSA, 2015).

\subsection{Study population}

Cattle found in Sedal district of Khamashi administrative zone were the target population. Three hundred Eight four local breeds were randomly selected and examined for the distribution and a abundance of tick species. All cattle sampled for this study were kept under extensive management system which varies with age, sex, and body condition.

\subsection{Study design}

A cross sectional study was conducted on the prevalence and risk factors associated with tick infestations and to identify different tick genera, and their species. The age of cattle were grouped as young (<1year), adult ( 1 to 3 years) and Old (>3years) (Nicholson and Butterworth, 1986).

\subsection{Sampling methods and determination of sampling size}

The cattle to be examined were selected by simple random sampling method, and multistage sampling strategy was used to determine appropriate sample size. The sample size was determined by using the formula given in Thrust field (2005). The expected prevalence of Ixodidae ticks of cattle in Sdal district of Khamashi administrative zone was assumed as 50\%. The parameters used were $95 \%$ confidence interval and $5 \%$ desired level of precision. By substituting these values in the formula, the sample size taken was $\mathrm{n}=384$

\subsection{Study methodology}

Firstly, the selected study animal was properly restrained and all tick samples were collected from half the body regions. Ticks were removed carefully and gently in a horizontal pull to the body surface. The collected ticks were preserved in universal bottles containing $70 \%$ ethanol and labeled with respect to predilection site, age, sex and date of collection, then transported to Asossa veterinary diagnostic laboratory for counting and identification. The ticks were counted and subsequently identified to genus and species level by using stereomicroscope, according to standard identification keys given by Walker et al. (2003).

3.5.1 Tick collection and preservation

Ticks were collected successfully from cattle after being restrained using strong crushes, by physical handling. The skin of each selected cattle was inspected for the presence of ticks then, ticks were manually collected by using forceps from different regions of the animals' body. All adult ticks (both sexes) were collected in universal bottles then the collected ticks were preserved in $70 \%$ ethyl alcohol and transported to Asossa veterinary diagnostic 
laboratory. The taxonomic key of was used to identify ticks species under Stereomicroscope (Walker et al., 2003). 3.5.2 Laboratory techniques for Tick examination

First ticks were seen grossly and classified to different genera levels. Ticks were identified into their species level depending up on their morphology and identification structures they have, such as color of scutum and conscutum, leg color, body, coxae one, coxa four and ventral plates. During tick identification in the laboratory the sample was put on petridish and the species was identified by examining under stereomicroscope.

\subsection{Data analysis}

The collected data from field were entered in to Microsoft excel spread sheet. Data was analyzed by using (SPSS) statistical package for windows version 20 to get data of descriptive statistics. The prevalence of tick infestation was calculated as the number of positive animals for specific tick species sampled divided by the total number of animals examined and multiplied by hundred. Furthermore, prevalence of each species of ticks was seen together with that of risk factors (Sex, body condition score and age).

\section{Results}

\subsection{Distribution of Tick in the Different origin (PA) in the Study Area}

The prevalence of tick infestation within different kebeles (PA) in Sdal district of Khamashi zone in current study out of $77.6 \%$ positive animals, Gokaya (23.4\%), Mequchaya (19\%), Diza (18.2\%) and Shawa (19\%). Presence of variation among peasant association is due to different geography and management (Table 1).

Table 1: Prevalence and distribution of tick in the different kebeles (PA) in study area

\begin{tabular}{lccc}
\hline Origin (PAs) & No. of animal & No. Positive Animal & Prevalence (\%) \\
\hline Diza & $87(22.65 \%)$ & 70 & 18.2 \\
Gokaya & $119(31 \%)$ & 90 & 23.4 \\
Shawa & $93(24.2 \%)$ & 65 & 17 \\
Meguchaya & $85(22.1 \%)$ & 73 & 19 \\
\hline Total & $\mathbf{3 8 4}(\mathbf{1 0 0 \% )}$ & $\mathbf{2 9 8}$ & $\mathbf{7 7 . 6}$ \\
\hline
\end{tabular}

\subsection{Prevalence and Distribution of Tick Genera and Species}

Genera: A total of 2687 ticks were collected from different body part of tick-infested cattle. From examined cattle $298(77.6 \%)$ were infested by tick. In general, Three Ixodidae tick genera and six species were identified from the study area. From identified genera; Amblyomma (80.3\%) (2157/2687) was the most abundant and widely distributed genus followed by genus, Rhipicephalus (Boophilus) 10.94 \% (294/2687). However, Hyalomma $8.75 \%$ (235/2687) was found to be the least abundant genera (Table 2).

Table 2. Distribution of tick genera in study area

\begin{tabular}{ll}
\hline Genus & Percentage of total tick genera \\
Amblyomma & $80.3 \%(2157 / 2687)$ \\
Rhipicephalus & $10.94 \%(294 / 2687)$ \\
Hyalomma & $8.75 \%(235 / 2687$ \\
\hline
\end{tabular}

\subsection{Distributions of Tick Species on the Animal}

From the collected tick, three genera were identified, such as Amblyomma, Rhipicephalus, and Hyalomma. Six species of ticks were identified; Amblyomma variegatum was the most abundant tick species comprising of (26.8\%) of the total collection. Multi species which were (15.8\%) and the second most abundant tick species of the whole collection. The third and the fourth widely distribute tick species was Hyalomma rufipes (12.5\%) and Rhipicephalus (B.) decolaratus (11.2\%). The three least abundant tick species were Rhipicephalus evertsi, Amblyomma variegatum and Rhipcephalus bursa, which was accounted for $5.7 \%, 4.8 \%$ and $0.8 \%$ of the total collection respectively (Table 3 ). 
Table 3. Distribution of tick species on the animal

\begin{tabular}{|c|c|c|}
\hline ick species & $\begin{array}{l}\text { Total Anim. Examined } \\
\qquad(n=384)\end{array}$ & $\begin{array}{l}\text { No. positive } \\
\text { animal }\end{array}$ \\
\hline
\end{tabular}

\begin{tabular}{|c|c|c|}
\hline Amblyomma variegatum & 103 & 26.8 \\
\hline Amblyomma gemma & 18 & 4.8 \\
\hline Rhipicephalus everetsi & 22 & 5.7 \\
\hline Rhipicephalus(B.) decoloratus & 43 & 11.2 \\
\hline Rhipicephalus bursa & 3 & 0.8 \\
\hline Hyalomma rufipes & 48 & 12.5 \\
\hline Multi Species* & 61 & 15.8 \\
\hline Total & 298 & 77.6 \\
\hline
\end{tabular}

Body Condition Score: Body conditions of the animals were also considered during examination and animals were divided into three body condition scores as shown in the below table. These are, good, medium and poor. Out of 384 animals examined 113 animals were in good body condition, out of which 92 (24\%) animals were positive for tick infestation, 134 animals were in medium body condition and out of these $99(25.8 \%)$ animals were positive for tick infestation and the rest 137 animals were poor body condition state and out of these 107 $(27.9 \%)$ animals were positive for tick infestation. These result shows that body condition have no significant relation with tick infestation that good body condition animal less affected by tick than medium body condition animal and poor body condition animal (Table 4).

Sex: Comparison was made on the prevalence of female and male. Out of animals sampled, the majority or $62 \%$ were Females while about $38 \%$ of them were males. The tick prevalence was $48.4 \%$ and $29.2 \%$ in Female and male respectively. However, there was no statistical $(\mathrm{P}>0.05)$ significance between the two sexes (Table 4).

Age: prevalence of tick infestation was Analyzed between different age category indicated that the difference in prevalence among the three age groups were relatively high in adult (Table 5) than the young and old groups with statistically significant variation $(\mathrm{P}<0.05)$. Tick infestation was statically significant in old animal as compared to other age category (Table 4)

Table 4. Prevalence of ixoded tick in relation to host risk factors

\begin{tabular}{lccccc}
\hline Risk Factors & Animal tested & $\begin{array}{c}\text { Number of positive } \\
\text { animal (\%) }\end{array}$ & P=value & OR (95\%) & 95\% CI \\
\hline Origin & & & & & \\
$\quad$ Gokaya & 119 & $90(23.4)$ & 0.075 & 1.960 & $0.935-4.109$ \\
$\quad$ Diza & 87 & $70(18.2)$ & 0.344 & 1.477 & $0.658-3.316$ \\
$\quad$ Shawa & 93 & $65(16.9)$ & 0.012 & 2.621 & $1.232-5.572$ \\
$\quad$ Mequchaya & 85 & $73(19.1)$ & - & - & - \\
BCS & & $107(27.9)$ & - & - & - \\
$\quad$ Poor & 137 & $99(25.8)$ & 0.463 & 0.791 & $0.422-1.481$ \\
$\quad$ Medium & 134 & $92(24)$ & 0.164 & 0.646 & $0.350-1.194$
\end{tabular}

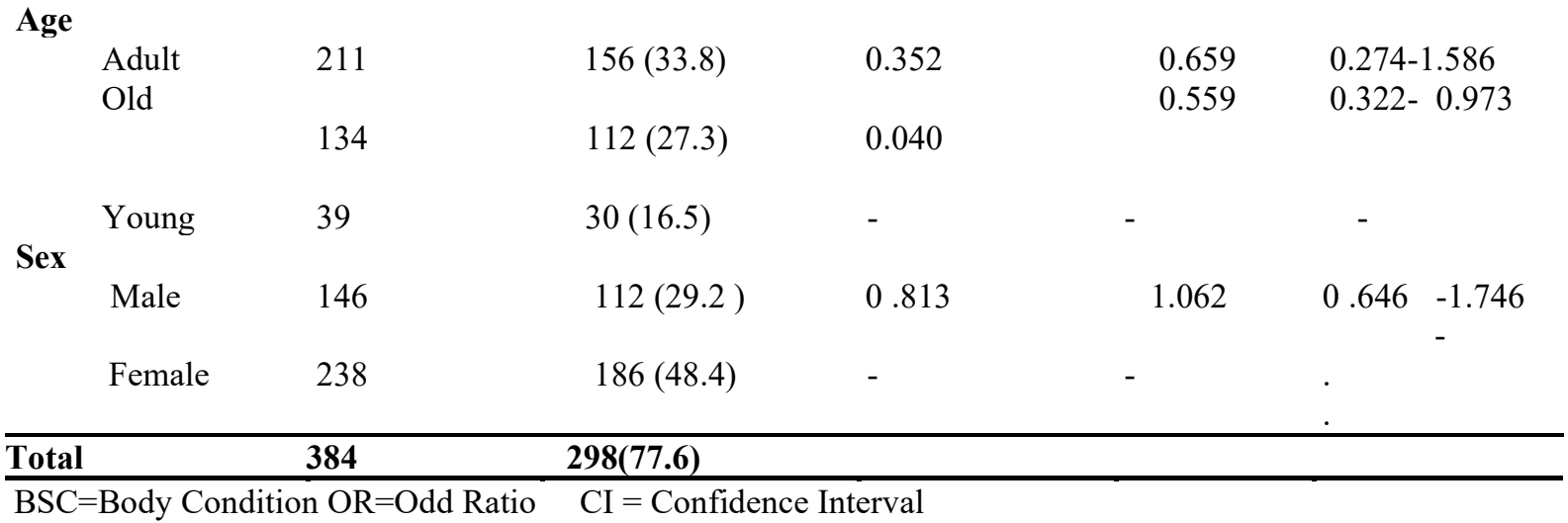

\section{Discussion}

In Ethiopia the distribution of the most tick species, vary greatly from one area to other area. In this survey, a total 2687 ticks were collected from a total of 298 , from local zebu breeds. The present study showed that $77.6 \%$ of 
tick prevalence. This finding is agreement with the findings of Nigatu and Teshome (2012), who reported an overall prevalence of $(89.4 \%)$. However, it is different from the findings of Belew and Mekonnen (2011) who reported an overall prevalence of $33.21 \%$. This difference could be due to the difference in the agro climatic condition of the study areas.

Three genera of hard ticks were identified, namely Amblyomma (80.3\%), Rhipicephalus (Boophilus) (10.94\%), Hyalomma (8.76\%) and six species of ticks namely A. variegatum (26.8\%), A. gemma (4.8\%), $R$. evertsi (5.7\%), R. (B.) decoloratus (11.2\%), H. Marginatum rufipes (12.5\%), Rhipicephalus bursa(0.8\%) and Multi species $(15.8 \%)$ were identified in the study area.

Amblyomma variegatum was the most abundant of all tick species comprising $26.8 \%$ of the collected ticks in the study sites. This result agreed with different reports done by other authors in different parts of Ethiopia such as Tessema and Gashaw (2010) in Asela, Belew and Mekonnen (2011) in Holeta Fanos et al. (2012) in Mizan Teferi, Seyoum (2005), Mehair (2004) in Awassa and Morka et al. (2014) in diga who as described A. varigatum as the first most abundant tick species collected. However, the study conducted in Wolaita zone by Dessie and Getachew (2006) and in Sebeta town by Gurmessa et al. (2015) showed that $A$. varigatum was the second abundant tick species which disagreed with current study. This variation may be due to the change in environmental conditions, with the result of global warming that highly affect the ecology of ticks. Change in temperature and rainfall have been reported to affect the distribution of diseases of vectors and tick borne diseases (Taylor et al., 2007).

Hyalomma marginatum rufipes was the second abundant tick collected with $12.5 \%$ of the total counts. This result disagreed with the finding of Tessema and Gashaw (2010) in Asela (2.5\%), Belew and Mekonnen (2011) in Holeta (1.86\%), Tegegn et al. (2016) in Bishoftu (4.7\%), Hussen (2009) in Bako, Tamiru (2008) in Assela and Tiki and Addis (2011) in and around Holeta also reported a prevalence of 1.2, 2.5, and 1.86\% respectively. The high prevalence of this tick species in current study area as stated could be due to the fact that H. marginatum rufipes is mostly found in arid parts of tropical Africa that receive about 250-650mm annual rain fall (Hoogstraal, 1956) and rare in western and central high land of the country. In Ethiopia altitude is often between 1000 to $2500 \mathrm{~m}$ above sea level and this makes the presence of this parasite to be very rare (pegram et al., 2001). Ticks are known to be distributed in different parts of the host's body.

Rhipicephalus (Boophilus) (decoloratus was the third widespread tick species of the cattle in the current study area $(11.2 \%)$. This result is disagreed with Sileshi et al. (2007) who described that B. decolaratus is the commonest and most wide spread tick in Ethiopia, collected in all administrative regions except in the Afar region. This is also not in line with Tamiru (2008) in Asela, and Teshome (2012) reported the highest prevalence of B. decolaratus $(80 \%)$ in the study areas.

Rhipicephalus evertsi-evertsi was found to be the fourth abundant $(5.7 \%)$ tick species in this study, which is comparable with the findings of Solomon et al. (2007), Tagegn et al. (2016) and Morka et al. (2014). Hoogstral (1996) described its wide distribution throughout the Ethiopian faunal region. Pegram et al. (2001) reported that this species had not zones or seasons; and it is also known to convey tick paralysis in Harar Ethiopia. According to Sileshi et al. (2007), R. evertsi-evertsi was collected throughout their study period, with the peak of abundance in January coinciding with the beginning of the rainy season and they also described that the discovery of this tick in that area was in line with its widespread occurrence in most parts of the country. The occurrence of this species in and around Wolaita zone was also reported by Dessie and Getachew (2006).

In this study, different animal related risk factors were studied to determine whether there is a significant variation in tick infestation between and among different groups of animals with suspected risk factors. During the study period, the prevalence of tick infestation was assessed between three age group cattle. The infestation of ticks on the animals was significantly $(\mathrm{p}<0.05, \mathrm{p}=0.04)$ influenced by age, with tick infestation was higher in adult animals as compared to young and old animals. Higher proportion may be due to outdoor management and long distant movement of adult animals to search for food and water compared to younger and older animals, so the chance of exposure is higher. This finding was also in agreement with the finding of (Yakhchali and Hasanzadehzarza, 2004) who reported tick infestation were higher in adults $(60.8 \%)$ than in youngest $(20 \%)$ in Oshnavich. Feseha (1997), Meaza et al. (2013) and Tessema and Gashaw (2010) also stated that a higher proportion in adults cattle than youngest. The prevalence of all tick species was higher in female animal than male animals.

The difference in prevalence was found statistically insignificant $(\mathrm{P}>0.05)$ between sex of cattle. Male animals were found less affected than females (in male $29.2 \%$ and in female it was $48.4 \%$ ) with no statistical significance $(\mathrm{P}-$ value $>0.05$ and $\mathrm{P}=0.81$ ). This result is in line with the other author in Benchi Maji by Tesfaheywet and Simeon (2013) but it disagreed with the previous works in Assosa by Bossena and Abdu (2012) that the difference in prevalence was found statistically significant between sex groups. This result is also concurred with the results of Kassa and Yalew (2012) where the p-values were greater than 0.05 . This might be due to equal opportunities of oxen and cows to tick infestation in their production as well as in their management condition.

The occurrence of tick infestation in three different body condition (Poor, medium and good) of animals 
shows the highest prevalence in poor body conditions (27.9\%), followed by medium body conditions $(25.8 \%)$ and $(24 \%)$ in good body condition. This was due to the fact that poor body scored animals have reduced resistance and are exposed to any kind of disease when grazing on the field, and good body conditioned animals are good resistance against infestation, so they become less infested than poor and medium sized animals.

\section{Conclusion and Recommendations}

Ticks are obligate blood feeding ectoparasites of vertebrates, among ectoparasite it cause the greatest economic loss in livestock population either by transmitting a wide variety of tick born disease or by affecting the health of animals as well as the quality of hide and skins. The study indicated that there was high prevalence of ticks in the study area that almost all sampled animals can have ticks on their body. Variable information on tick species distribution and dynamics are very essential to assess the economic loss encountered due to tick infestation and also to identify the appropriate measure of tick control. The important and abundant tick species investigated in the study area were Amblyomm varigatum, Hyalomma rufipes, Rhipicephalus (B.) decolaratus, Rhipicephalus evertsi, Amblyomm gemma and Rhipicephalus bursa. The result of this survey indicates that economically important ticks are widespread throughout the study areas and their presence in abundance is alerting. However, the attention given to controlling the infestation had not been sufficient. In line with the above conclusion the following recommendations are forwarded:

$>$ Tick control program (application of acaricides) should be continued with an increasing frequency of application in wet months.

$>$ More attention should be given to the selection of resistance cattle breeds and types, and good performance with regards to production of local breeds.

$>$ Appropriate pasture management in communal grazing area is important.

\section{References}

Belew, T. and Mekonnen, A., 2011. Distribution of Ixodidae ticks on cattle in and around Holleta Town, Ethiopia. Veterinary Journal, 7(6): 527-531.

Bossena, F. and Abdu, M., 2012. Survey on the Distribution of Tick Species in and Around Assosa Town, Ethiopia. Research Journal of Veterinary Science, 5: 32-41.

CSA (Central Statistical Authority), (2015). Agricultural Sample Survey, Statistical Bulletin, Ethiopia, Addis Ababa,Pp. 39-47.

CSA, 2013. Federal Democratic Republic of Ethiopia, Central Statistical Authority, Agricultural Sample Survey (2012/2013). Report on Livestock and Livestock Characteristics (Privet and Peasant Holdings), Addis Ababa, PP: 9-20.

Dessie, S. and Getahun, 2006. Cattle Tick Dynamics in Different Agro-Ecological Zones of Wolayta, Southern Ethiopia. Master thesis, Faculty of Veterinary Medicine, Addis Ababa University, Bishoftu, Pp: 18-83.

Eyo, J.E., Ekeh, F.N., Ivoke, N., Atama, C.I., Onah, I.E., Ezenwaji N.E. and Ikele, C.B., 2014. Survey of Tick Infestation of Cattle at Four Selected Grazing Sites in the Tropics. Global Veterinarians, 12: 479-486.

Fanos, T., Gezali, A. Sisay, G., Bersissa, K. and Tariku, J., 2012. Identification of tick species and their preferred site on cattle's body in and around Mizan Teferi. School of Veterinary Medicine, Addis Ababa University, College of Veterinary Medicine, Haramaya University and College of Agriculture and Veterinary Medicine, Jimma University. Journal of Veterinary Medicine and Animal Health, 4(1):1-5.

Gebre, S., Nigist, M. and Kassa, B., 2001. Seasonal Variation of Ticks on Calves at Sebetain Western Shewa Zone. Ethiopian Veterinary Journal, 7: 17-30.

Gurmessa, H., Makurim, A., Solomon, G. and D. Banti, 2015.Identification of bovine tick species and their prevalence in and around Sebeta town. DVM Thesis, Faculty of Veterinary Medicine, Jimma University, Jimma, Ethiopia.

Hoogstraal, H., 1996. African Ixodidae. Ticks of Sudan (with special to Equatorial province and with preliminary reviews of the genera Boophilus, Margaropus, Hyalomma) Res. Rep. N.M., 005050.29 - 07. U.S Government Department Navy, Bur. Med. Surg., Will behington, D.C., Pp: 200-1101.

Hussen, Y., 2009. Preliminary survey of cattle tick species and burden in and around Bako town. DVM Thesis, school of veterinary medicine Jimma University, Jimma, Ethiopia.

Kassa, S.A. and Yalew, A., 2012. Identification of Ixodide ticks of cattle in and around Hararamaya district, Eastern Ethiopia. Scientific Journal of Crop Science, 1(1): 32-38.

Lorusso, V., Picozzi, K., deBronsvoort, B.M., Majekodunmi, A., Dongkum, C., Balak and G., Welburn, S.C, 2013. Ixodid Ticks of Traditionally Managed Cattle in Central Nigeria: Where Rhipicephalus (Boophilus) microplus. Parasit Vectors, 6: 171.

Maruf, M.C., 2008. Prevalence of tick and tick borne diseases in cattle communal rangelands in the high land areas of the Eastern Cape provinces. MSc Thesis, University of Fort Hare, Alice.

Meaza, G., Abdu M., and Yisehak, K., 2013. Determination of the Prevalence of Ixodid Ticks of Cattle Breeds, 
Their Predilection Sites of Variation and Tick Burden Between Different Risk Factors in Bahir Dar, Ethiopia, Global Veterinaria, 13(4): 520- 529.

Mehari, B., 2004. Distribution of livestock tick species in Awassa area. DVM Thesis, Faculty of Veterinary Medicine, Addis Ababa University, Bishoftu, Ethiopia. Pp: 6-29.

Mekonnen, B., Hussen, I. and Bedane, B., 2001. The distribution of Ixodid ticks (Acari: Ixodidae) in central Ethiopia. Journal of Veterinary Research, 68: 243-251.

Mesfin, T. and Lemma, M., 2001. The Role of Traditional Veterinary Herbal Medicine and Its Constraints in the Animal Health Care System in Ethiopia. In: Medhin, Z. and Abebe, D., Eds., Conservation and Sustainable Use of Medicinal Plants in Ethiopia, Institute of Biodiversity Conservation and Research, Addis Ababa, Pp: 22-28.

MoARD, 2008. The Effect of Skin and Hide Quality on Domestic and Export Market and Evaluation of the Campaign against Ectoparasites of Sheep and Goat in Amhara, Tigray and afar Region. Official Report to Region and Other Sectors, Addis Ababa.

Morka, A., Zegeye, A. and. Eyob, H., 2014. -Prevalence of Ixodid Ticks on Cattle in and Around Diga Town, West Ethiopia, School of Veterinary Medicine, Wollega University, Nekemte. Europ. J. Biol. Sci., 6 (1): $25-$ 32.

Nicholson, M.J. and Butterworth, M.H., 1986. A guide to condition scoring of zebu cattle. International Livestock Centre for Africa, Addis Ababa, pp. 1-50.

Nigatu, K. and Teshome, F., 2012. Population Dynamics of ectoparasite in Western Amhara National Regional States, Ethiopia. Journal of Vet. Med. And Animal Health, 4: 22-26.

Olwoch, J.M., Revers, B. and Van Jaarsveld, A.S., 2009. Host Parasite Distribution Patterns under Simulated Climate: International Journal of Current Research, 4: 073-076.

Onu, S.H. and Shiferaw, T.Z., 2013. Prevalence of Ectoparasite Infestations of Cattle in Bench Maji Zone, Southwest Ethiopia. Veterinary World, 6: 291-294.

Pegram, R.G., 2001. Getting a Handle on Tick Control: A Modern Approach May Be Needed. The Veterinary Journal, 161: 227-228.

Rajput, Z.I., .Hu, S.H, Chen, W.J., Arijo, A.G. and Xiao, C.W., 2006. Importance of Ticks and Their Chemical and Immunological Control in Livestock. Journal of Zhejiang University Science B, 7: 912-921.

Regasa, T.D., Kebede Tsegay, A. and Waktole, H., 2015. Prevalence of Major Ectoparasites of Calves and Associated Risk Factors in and around Bishoftu Town. African Journal of Agricultural Research, 10: $1127-$ 1135 .

Seyoum, Z., 2001. Study of Ticks and Tick-Borne Diseases on Cattle at Girana Valley in the North Wollo Zone. Proceeding of the Ethiopian Veterinary Association, 15.

Seyoum, Z., 2005. Distribution and host parasite relationship of ixodids ticks in eastern Amhara, Kombolcha Veterinary Laboratory, kombolcha, Ethiopia. Pp. 34-47.

Sileshi, M., Pegram, R.G., Solomon, G., Abebe, M., Yilma J. and Sileshi, Z., 2007. A synthesis of review of Ixodids (Acari: Ixodidae) and Argas (Acari: Argasidae) ticks in Ethiopia and their possible role in diseases transmission. Ethiopia Vet. J. 2:80-87

Solomon, G. and Kassa, G.P., 1996. Studies on the development and Survival of R. pulchellus and A. gamma under field condition. Ethiop. Vet. J., 9: 134-139.

Solomon, G., Nigist, M. and Kassa, B., 2007. Seasonal variation of ticks on calves at Sebata in Western Shoa Zone. Ethiopia. Vet. J., 7:2.

Tadesse, B. and Sultan, A., 2014. Prevalence and Distribution of Tick Infestation on Cattle at Fitche Selale, North Shewa, Ethiopia. Livestock Research for Rural Development, 26: 45-67

Tamiru, T., 2008. A survey of Bovine tick species in and around Assella Town. DVM thesis, Jimma University College of Agriculture and Veterinary Medicine; Jimma, Ethiopia.

Tegegn, T., Yosef, D. and Nuraddis, I., 2016. Prevalence and Species Composition of Ticks Infesting Cattle In and Around Bishoftu Town. Jimma University, School of Veterinary Medicine. Global Veterinaria, 16 (3): 238-246. 20.

Tesfahewet, Z.S. and Simeon, H.O., 2013. Prevalence of ectoparasite infestations of cattle in Bench Maji zone, southwest Ethiopia. Veterinary World, 6(6): 291-294.

Teshome, F. and Nigatu, K., 2012. Population dynamics of cattle ectoparasites in Western Amhara National Regional State, Ethiopia. J. Vet. Med. Anim. Health, 4(1):22-26.

Tessema, T. and Gashaw, A., 2010. Prevalence of ticks on local and crossbreed cattle in and around Asela Town, South East, Ethiopia, Amber Animal Health Department, East Gojam, Ethiopia Vet. J., 14(2):79-89.

Thrusfield, M., 2005. Veterinary Epidemiology, Veterinary clinical studies, Royal (Dick) school of veterinary studies university of Edinburgh. 3rd ed. Blackwell Science Ltd., Pp. 180-233.

Tiki, B. and. Addis, M: 2011.Distribution of ixodide ticks, on cattle in and around Holeta town, Ethiopia. Glob. vet. 7(6):527-531. 
Walker, A.R., Bouattour, A., Camicas, J.L., Estrada-Pena, A., Horak, I.G., Latif, A.A., Pegram, R.G., Prestonand, P.M and Wollega, D., 2003. Survey of Ticks and Tick Born Disease in Eight Domestic Animals in and round Bishoftu. DVM Thesis, Facility of Veterinary Medicine Bishoftu, Addis Ababa University, Eastern Showa, PP: 1-79.

Yakhchali, M. and Hasanzadehzarza, H.S., 2004. Study on some ecological aspects and prevalence of different species of hard ticks (Acarina: Ixodidae) on cattle, buffalo and sheep in Oshnavieh suburb. Pajouhesh-vaSazandegi in Anim. Fish. Sci., 63: 30-35.

Yiwombe, K., 2013. An investigation to Boophilus tick (blue tick) T. Doctoral Dissertation, Midlands State University. 